\section{Improved PADDY-Large model including lateral seepage loss from paddy fields to predict pesticide behavior in river basins}

\author{
Keiya InAO, ${ }^{*}$ Nobusuke IWASAKI, \\ Ikuko Kitayama and Takeshi Horio \\ National Institute for Agro-Environmental Sciences, Kannondai, Tsukuba, \\ Ibaraki 305-8604, Japan
}

(Received November 19, 2015; Accepted February 4, 2016)

\begin{abstract}
We developed an improved simulation model for predicting pesticide concentrations in river basins based on PADDY-Large, which includes lateral seepage loss of pesticides from paddy fields. Based on the structure of typical Japanese paddy fields, pesticide transport process due to lateral seepage through bunds was modeled as a compartment system consisting of pore water and soil particle. The model was validated with concentrations measured by monitoring paddy pesticides in a tributary of the Sakura River in Japan. The improved model by including loss of pesticides due to lateral seepage through bunds successfully simulated temporal changes in the pesticide concentrations. () Pesticide Science Society of Japan

Keywords: environmental fate, paddy condition, simulation model, lateral seepage, river basin.
\end{abstract}

\section{Introduction}

Public concerns regarding the adverse effects of pesticides in runoff from paddy fields on aquatic ecosystems and drinking water are increasing. Several pesticides commonly used in rice paddy fields have been detected in river systems in Japan by means of monitoring. ${ }^{1-5)}$ Recently, models at the field-plot scale (e.g., PADDY ${ }^{6-8)}$ and PCPF-1 ${ }^{9-11)}$ ) have been developed to simulate the behavior of rice paddy pesticides in Japan. The PADDY-Large model was developed to predict pesticide concentrations in river basins, and the model considers pesticide transport processes (surface runoff and spray drift) to surrounding waters. ${ }^{12-14)}$

In the pesticide registration scheme of the Ministry of the Environment of Japan, which addresses ecological risk and water pollution, ${ }^{15)}$ the predicted environmental concentration of each pesticide is calculated using environmental models based on the

\footnotetext{
* To whom correspondence should be addressed.

E-mail: keinao@affrc.go.jp

Published online April 23, 2016

(c) Pesticide Science Society of Japan
}

standard scenario for the pesticide's use. In the predicted environmental concentration calculation, in addition to surface runoff and spray drift, lateral seepage loss of pesticides from paddy fields is also considered. Sudo et al. ${ }^{16)}$ reported that the cumulative loss of the herbicide pretilachlor due to the horizontal percolation flow of paddy water ranged from 7.4 to $16.3 \%$ of the applied mass in paddy fields with a large water-storage capacity when drainage gates were set to a height $>10 \mathrm{~cm}$, and they found that the loss increased proportionally with the percolation rate. However, the PADDY-Large model does not consider the lateral seepage process of pesticides into river systems.

The objective of the present study was to develop an improved PADDY-Large model that includes lateral seepage loss of pesticides from paddy fields through bunds. To validate the model, values calculated by the improved model were compared with values measured by monitoring paddy pesticide concentrations in a tributary of the Sakura River in Japan.

\section{Materials and Methods}

The PADDY-Large model ${ }^{12-14)}$ was originally developed to predict pesticide concentrations in surface water and sediment in river basins based on pesticide behavior in paddy fields. The pesticide transport processes from paddy fields into drainage canals included in the model were (1) surface runoff due to overflow or drainage of paddy water and (2) spray drift during pesticide treatment. The latest version of the model was enhanced through coupling with geospatial information on watershed properties to improve the precision of the model. ${ }^{14)}$

In this study, we improved the PADDY-Large model by including lateral seepage loss of pesticides from paddy fields. A standard rectangular paddy plot $(30 \times 100 \mathrm{~m})$ was considered to express the lateral seepage process of pesticides mathematically. Figure 1a shows a cross-sectional view of a typical Japanese paddy field. ${ }^{17-19)}$ One shorter side (30 m long) of the paddy plot bounded by a bund is adjacent to a drainage canal, but the other side is not. Since there have been no reports on the details of the lateral seepage pathway in the soil of actual paddy plots, we made the following simplified assumptions for the seepage pathway: (1) percolation water flows out via the straight path from the edge of the paddy plot to the water surface of the drainage canal, and (2) the cross-sectional area of the bund soil responsible for the seepage process $\left(S_{\mathrm{B}}, \mathrm{m}^{2}\right)$ fluctuates based on the paddy water depth $(h, \mathrm{~m})$ shown in Fig. 1a. ${ }^{19)}$ In this study, $S_{\mathrm{B}}$ is calculated by the approximate expression as

$$
S_{\mathrm{B}} \cong 2.15 \sqrt{2} h
$$

Note that the estimated area $\left(S_{\mathrm{B}}\right)$ is probably smaller than that of actual paddy plots because the seepage pathway through the paddy soil at the surface or subsurface layer was not considered in this study, and underestimation of the area can cause overes- 


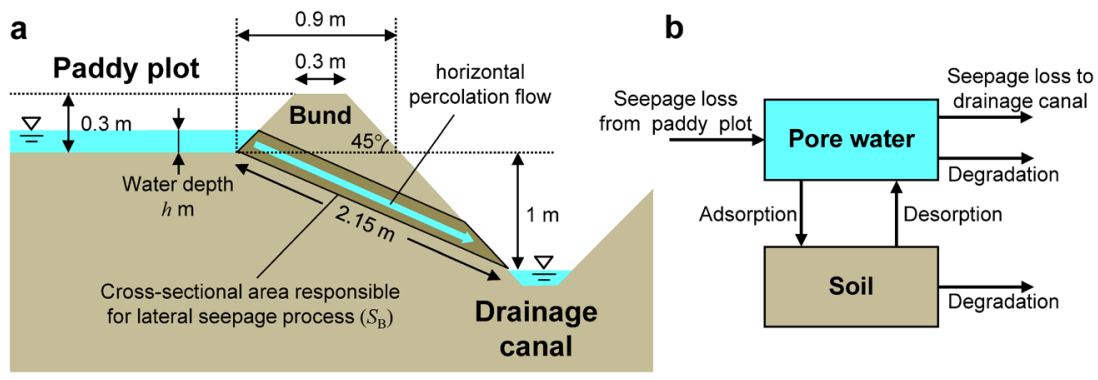

Fig. 1. (a) Cross-sectional view of a typical paddy field and (b) compartment system of the pesticide behavior in the bund's soil layer responsible for the seepage included in the improved PADDY-Large model.

timation of the seepage loss of pesticides to the drainage canal in the model simulation.

In general, pesticide transport and fate in soil, including the lateral seepage process, can be modeled using the advection-diffusion equation. ${ }^{20)}$ However, the seepage pathway defined in this study is provisional, and it is difficult to adequately consider the preferential water flow pathways through macropores and cracks in bund soil reported previously ${ }^{16)}$ for an advection-diffusion model. Therefore, a compartmentalized approach was employed in this study. The bund soil layer is composed of pore water and soil compartments, which are assumed to be completely mixed systems (i.e., pesticides are well mixed and dispersed uniformly in the compartments) (Fig. 1b). If the pore spaces of the bund's soil layer are filled with water (saturated condition), the volume of the pore water $\left(V_{\mathrm{W}, \mathrm{B}}, \mathrm{m}^{3}\right)$ and mass of the soil $\left(M_{\mathrm{S}, \mathrm{B}}\right.$, ton $)$ are as follows:

$$
\begin{gathered}
V_{\mathrm{W}, \mathrm{B}}=30 S_{\mathrm{B}} \varepsilon_{\mathrm{B}} \\
M_{\mathrm{S}, \mathrm{B}}=30 S_{\mathrm{B}} \rho_{\mathrm{b}, \mathrm{B}}
\end{gathered}
$$

where

$\varepsilon_{\mathrm{B}}=$ porosity of the bund soil $\left(\mathrm{cm}^{3} / \mathrm{cm}^{3}\right)$ and

$\rho_{\mathrm{b}, \mathrm{B}}=$ bulk density of the bund soil $\left(\mathrm{g} / \mathrm{cm}^{3}\right)$.

If the depth of the paddy water $(h)$ is constant (i.e., $V_{\mathrm{W}, \mathrm{B}}$ and $M_{\mathrm{S}, \mathrm{B}}$ are constant), and considering the pesticide transport due to seepage loss from paddy plot to drainage canal by horizontal percolation, adsorption and desorption between pore water and the soil, and degradation in the pore water and soil (Fig. 1b), the chemical mass-balance equations for the bund's soil layer are as follows:

$$
\begin{aligned}
V_{\mathrm{W}, \mathrm{B}} & \frac{\mathrm{d} C_{\mathrm{W}, \mathrm{B}}}{\mathrm{d} t} \\
= & Q_{\mathrm{h}} C_{\mathrm{W}, \mathrm{P}}-Q_{\mathrm{h}} C_{\mathrm{W}, \mathrm{B}}-M_{\mathrm{S}, \mathrm{B}}\left(k_{\mathrm{ads}, \mathrm{B}} K_{\mathrm{f}, \mathrm{B}} C_{\mathrm{W}, \mathrm{B}}^{1 / n, \mathrm{~B}}-k_{\mathrm{des}, \mathrm{B}} C_{\mathrm{S}, \mathrm{B}}\right) \\
& -V_{\mathrm{W}, \mathrm{B}} k_{\mathrm{dw}, \mathrm{B}} C_{\mathrm{W}, \mathrm{B}}
\end{aligned}
$$

for the pore water compartment and

$$
\begin{aligned}
M_{\mathrm{S}, \mathrm{B}} \frac{\mathrm{d} C_{\mathrm{S}, \mathrm{B}}}{\mathrm{d} t}= & M_{\mathrm{S}, \mathrm{B}}\left(k_{\mathrm{ads}, \mathrm{B}} K_{\mathrm{f}, \mathrm{B}} C_{\mathrm{W}, \mathrm{B}}^{\mathrm{l} / n, \mathrm{~B}}-k_{\mathrm{des}, \mathrm{B}} C_{\mathrm{S}, \mathrm{B}}\right) \\
& -M_{\mathrm{S}, \mathrm{B}} k_{\mathrm{ds}, \mathrm{B}} C_{\mathrm{S}, \mathrm{B}}
\end{aligned}
$$

for the soil compartment. The subscripts B and P denote the bund and paddy field, respectively, and $C_{\mathrm{W}}=$ pesticide concentration in the water $(\mathrm{mg} / \mathrm{L})$,
$C_{\mathrm{S}}=$ pesticide concentration in the soil $(\mathrm{mg} / \mathrm{kg})$,

$t=$ time (days),

$Q_{\mathrm{h}}=$ volumetric flow rate of horizontal percolation $\left(\mathrm{m}^{3} /\right.$ day),

$k_{\mathrm{ads}}=$ adsorption rate constant (1/day),

$k_{\mathrm{des}}=$ desorption rate constant (1/day),

$K_{\mathrm{f}}=$ Freundlich adsorption coefficient $\left(\mathrm{cm}^{3} / \mathrm{g}\right)$,

$1 / n=$ Freundlich exponent (dimensionless),

$k_{\mathrm{dw}}=$ first-order degradation rate constant in water (1/day), and

$k_{\mathrm{ds}}=$ first-order degradation rate constant in soil (1/day).

The pesticide concentration in paddy water $\left(C_{\mathrm{W}, \mathrm{P}}\right)$ in Eq. (4) can be calculated using the PADDY model. ${ }^{6-8)}$ These differential equations can be solved by using the techniques reported previously, ${ }^{6,7)}$ and the solutions of the equations give the pesticide concentrations in the pore water and soil compartments as a function of time. A computer simulation program was developed with the Visual Basic for Applications software (ver. 7.0) in Microsoft Excel 2010. The improved PADDY-Large model simulates the pesticide concentrations in the drainage canal, tributary stream (main canal), and main river in sequence based on the seepage process as well as surface runoff and spray drift. A detailed description was reported previously. ${ }^{12-14)}$

To validate the improved PADDY-Large model, we monitored paddy pesticide concentrations in the Sakasa River, a tributary of the Sakura River, in southern Ibaraki Prefecture, Japan (Fig. 2). In the sub-basin, rice seedlings were transplanted from late April to early May 2012. Analysis of the geographic information system (GIS) data (land use ${ }^{21)}$ and cultivated soil ${ }^{22)}$ ) indicated that the area of the paddy fields was $161.6 \mathrm{ha}$, corresponding to $17 \%$ of the sub-basin. Most paddy fields had Gray Lowland soils, with an average total carbon content of $1.7 \%$. Water samples were collected once a week at the Futatsu Bridge (river width, 4-5 m), which is located midway along the course of the river, from April to August 2012. The volumetric flow rates were measured at the sampling point. Target pesticides were extracted from each water sample with a solid-phase extraction cartridge, and the pesticide concentrations were quantified using a liquid chromatograph with a tandem mass spectrometer. The details of the sampling and analytical methods were reported previously. ${ }^{4}$ Watershed properties (i.e., paddy field area and soil type) in the target sub-basin that were required as model inputs were analyzed by using a method based on a GIS that was developed previously. ${ }^{14)}$ 
Table 1. Model input parameters for the three herbicides ${ }^{22-24)}$

\begin{tabular}{lccc}
\hline \multicolumn{1}{c}{ Parameter } & Bensulfuron-methyl & Bromobutide & Daimuron \\
\hline Usage rate in the target sub-basin $(\%)^{a)}$ & 24.0 & 41.4 & 24.8 \\
Recommended application rate $(\mathrm{g}$ a.i./ha) & 51 & 900 & 450 \\
Molecular weight $(\mathrm{g} / \mathrm{mol})$ & 410.4 & 312.25 & 268.4 \\
Water solubility $(\mathrm{mg} / \mathrm{L})$ & $67\left(25^{\circ} \mathrm{C}, \mathrm{pH} 7\right)$ & $3.54\left(25^{\circ} \mathrm{C}\right)$ & $0.79\left(20^{\circ} \mathrm{C}\right)$ \\
Vapor pressure $(\mathrm{Pa})$ & $<1.2 \times 10^{-6}\left(25^{\circ} \mathrm{C}\right)$ & $5.92 \times 10^{-5}\left(25^{\circ} \mathrm{C}\right)$ & $4.5 \times 10^{-7}\left(20^{\circ} \mathrm{C}\right)$ \\
Soil adsorption constant based on organic carbon $\left(K_{\mathrm{oc}} \mathrm{mL} / \mathrm{g}\right)^{b)}$ & 2481 & 213 & 940 \\
Half life in water (days) & 49.5 & 35 & 2.7 \\
Half life in soil (days) & 14 & 29.5 & 77 \\
\hline
\end{tabular}

a) Estimated from the shipment data in Ibaraki Prefecture in 2012 and the recommended application rate. ${ }^{b}$ Average for four soils.

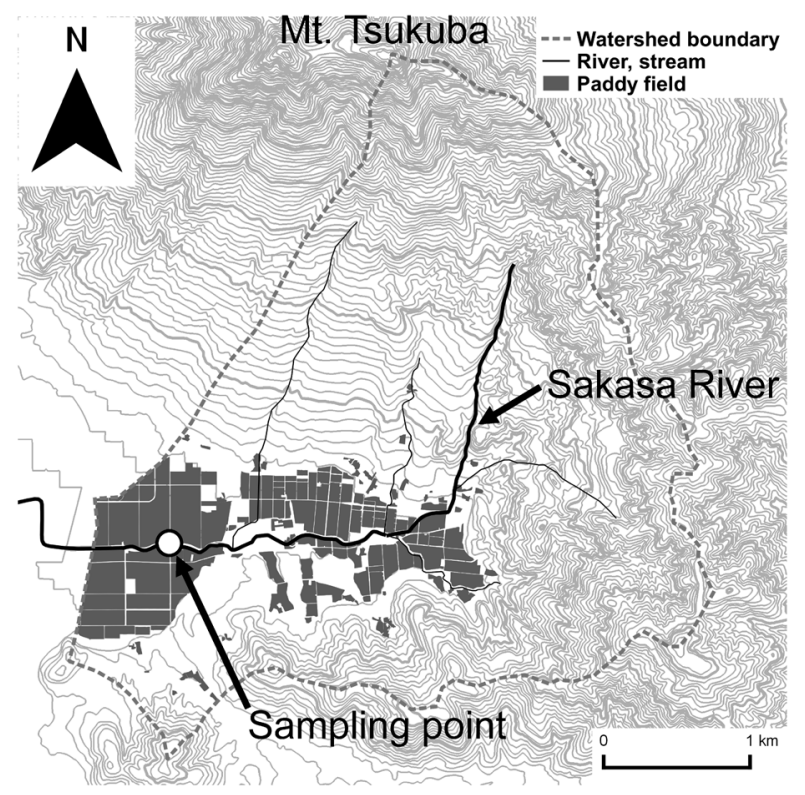

Fig. 2. Map of the studied sub-basin and location of the monitoring station.

\section{Results and Disscussion}

Based on the results of the monitoring studies, we selected three herbicides for model validation: bensulfuron-methyl, bromobutide, and daimuron, all of which were widely used in the subbasin. The physicochemical properties of the herbicides ${ }^{23-25)}$ were used in the model simulation (Table 1). In the model simulation of the herbicide concentrations at the sampling point (Fig. 2 ), the area of the paddy fields under rice cultivation was estimated from the cropping ratio for paddy rice in Ibaraki Prefecture (78\%) reported in the Statistical Report on Agriculture, Forestry and Fisheries in 2012. ${ }^{26)}$ The usage rates of the herbicides in the sub-basin were estimated from the shipment data in Ibaraki Prefecture in 2012 27 ) and the recommended application rates of the products containing those herbicides (Table 1). Distributions of the application dates for the herbicides were derived from the distribution of rice transplanting dates in Ibaraki
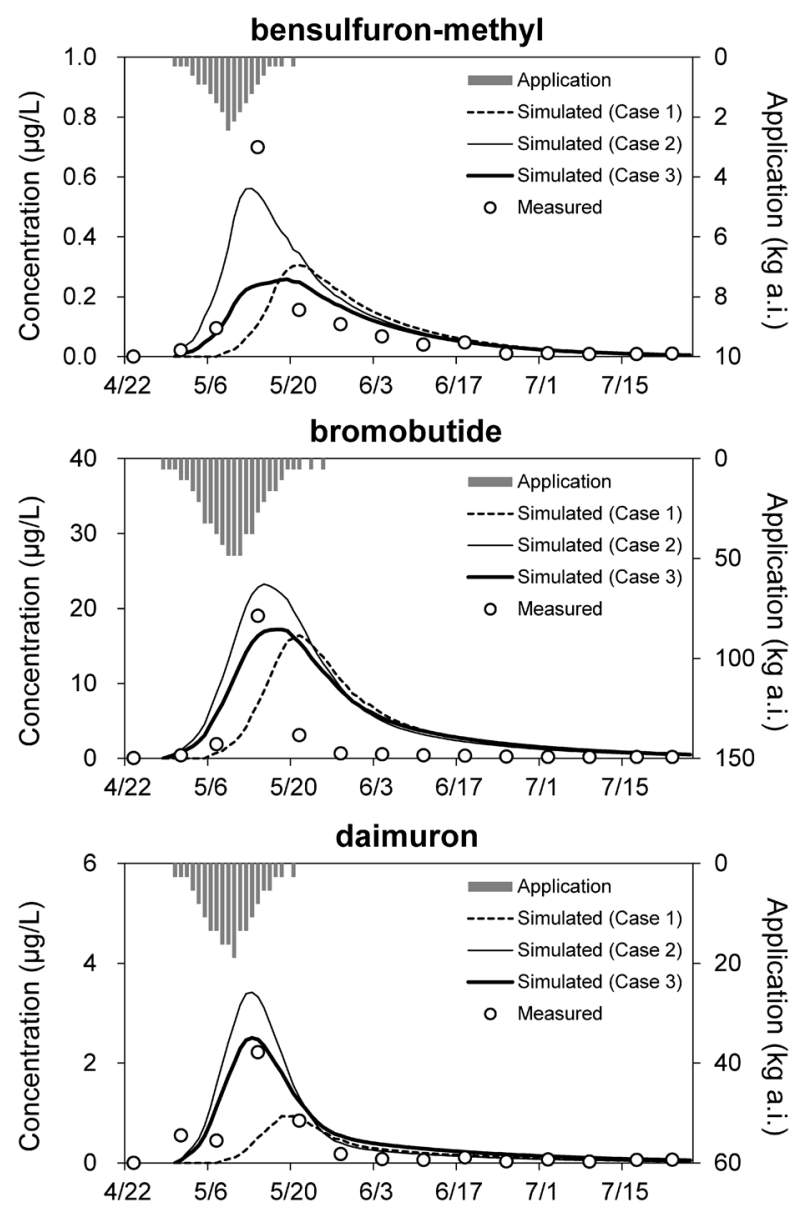

Fig. 3. Simulated and measured data for three herbicides in the Sakasa River in 2012. Case 1 indicates the simulated results without consideration of the seepage process, case 2 indicates the results with consideration of the seepage process and excluding adsorption and desorption kinetics, and case 3 indicates the results including both the seepage and adsorption and desorption kinetics. Downward bar graphs represent the estimated amount of the herbicides applied daily in the sub-basin.

Prefecture in 2012 28 ) and the recommended application timing of the products, as reported previously. ${ }^{14)}$ The measured concentrations of bensulfuron-methyl, bromobutide, and daimuron in 
the river water peaked at $0.70,19.0$, and $2.22 \mu \mathrm{g} / \mathrm{L}$, respectively, about 1 week after transplanting (mid-May) and then decreased rapidly in early June (Fig. 3).

For the model simulation of the water balance in the paddy fields, we made the following assumptions by considering the water management in the sub-basin ${ }^{29)}$ : (1) the depth of paddy water was constant, with an average of $5 \mathrm{~cm}$; (2) the paddy water was regulated to prevent surface outflow for 7 days after the herbicide application (water-holding period, WHP); (3) the surface outflow rate was constant, with an average of $0.25 \mathrm{~cm} /$ day after the WHP; and (4) horizontal percolation occurs constantly at an average flow rate of $6.6 \mathrm{~m}^{3} /$ day, corresponding to the fall in paddy water level of $0.22 \mathrm{~cm} /$ day. The river flow rate at the sampling point was set at a median value of $0.23 \mathrm{~m}^{3} / \mathrm{s}$ in May, which corresponds to the application and detection periods of the herbicides.

The temporal patterns of concentration changes in the river water simulated by the improved PADDY-Large model with and without consideration of the seepage process are shown in Fig. 3. The simulated maximum concentration without consideration of seepage (Case 1) was underestimated based on the measured values. In addition, there were time lags for the initiation of the concentration increase in the simulation. This result suggests that farmers may have used WHPs shorter than 7 days or that seepage makes a large contribution to pesticide loss from paddy fields. In contrast, the peak time of the simulated concentrations with consideration of the seepage process and excluding adsorption and desorption kinetics (Case 2) coincided with that of the observed concentrations. This is in agreement with results reported by Sudo et al., ${ }^{16)}$ in which the increase in the concentration of pretilachlor in horizontal percolation water was observed immediately after application. However, the simulated results overestimated the measured concentrations for bromobutide and daimuron. Considering the seepage process and including adsorption and desorption kinetics (Case 3), simulated peak concentrations were lower than those in Case 2, which resulted in better agreement between simulated and measured concentrations. This result is comparable to the report of Sudo et al., ${ }^{16)}$ in which the maximum concentration of pretilachlor in horizontal percolation water was lower than that in paddy water due to the adsorption and degradation process in paddy soil. These results suggest that paddy water flows out into the drainage canal at a constant rate (the estimated mean residence time of the seepage water in the bund soil was $10.2 \mathrm{hr}$ in this study) but pesticide loss was reduced significantly due to adsorption on the bund soil during the seepage process.

Goodness of fit was assessed using the root-mean-square error (RMSE) ${ }^{8)}$ In general, the lower the RMSE, the better the agreement between measured and simulated data. For bensulfuron-methyl, bromobutide, and daimuron, the RMSE (\%) values in the three cases were calculated (Table 2). Except for bensulfuron-methyl, the RMSE values of the herbicides were lowest in Case 3, which included both the seepage process and adsorption and desorption kinetics. However, the peak shapes of the
Table 2. Statistical analysis of the measured and simulated concentrations of three herbicides in river water based on the root-mean-square error (RMSE)

\begin{tabular}{lccc}
\hline \multirow{2}{*}{\multicolumn{1}{c}{ Pesticide }} & \multicolumn{3}{c}{ RMSE (\%) } \\
\cline { 2 - 4 } & ${\text { Case } 1^{a)}}$ & Case 2 $^{b)}$ & Case 3 ${ }^{c}$ \\
\hline Bensulfuron-methyl & 152.8 & 71.4 & 116.9 \\
Bromobutide & 241.8 & 226.6 & 191.7 \\
Daimuron & 125.4 & 115.3 & 73.0 \\
\hline
\end{tabular}

a) Simulation without consideration of the seepage process. ${ }^{b}$ Simulation with consideration of the seepage process and excluding adsorption and desorption kinetics. ${ }^{c}$ Simulation including both the seepage process and adsorption and desorption kinetics.

simulated concentration curves were broader than those of the measured results, probably because overestimation of the seepage loss of herbicides raised the concentration in river water in the model simulation, as mentioned previously. In the model simulation on the assumption that the cross-sectional area of the bund soil for the seepage process $\left(S_{\mathrm{B}}\right)$ is twice as large as the setup value in Case 3, the peak concentrations decreased to about $80 \%$ of those in Case 3 . Therefore, precise information about the seepage pathway is required for accurate model prediction of pesticides in river water. For bensulfuron-methyl, there was a large margin of error between the measured and simulated data at the peak concentration in Case 3, probably because the setup for the estimated usage rate of this herbicide did not coincide with the actual usage rate in the sub-basin. Consequently, we feel that a reasonable agreement was obtained in the simulation by the improved PADDY-Large model.

\section{Conclusion}

In this study, an improved PADDY-Large model was developed that included the lateral seepage process of pesticides from paddy fields, and the model was validated to improve the accuracy of predicted pesticide concentrations in river water. The model performance regarding the seepage process was improved measurably. However, the improvement of the model was not enough to estimate an actual concentration of pesticides in river water. Although more research on the seepage process, especially the seepage pathway in the bund soil and additional validation of the model with other pesticides in this and other basins, is necessary, we anticipate that this model will be useful for assessing the ecological risks of paddy pesticides.

\section{Acknowledgements}

This work was supported in part by the Environment Research and Technology Development Fund (5C-1102) of the Ministry of the Environment of Japan. The authors are grateful to Mr. Y. Iizumi, Mr. H. Iino, Mr. H. Yamaguchi, and Mr. T. Ara of the National Institute for Agro-Environmental Sciences for their assistance with sample collection.

\section{References}

1) A. Tanabe, H. Mitobe, K. Kawata, A. Yasuhara and T. Shibamoto: J. Agric. Food Chem. 49, 3847-3852 (2001). 
2) M. Sudo, T. Kunimatsu and T. Okubo: Water Res. 36, 315-329 (2002).

3) S. Ishihara, M. Ishizaka, T. Horio, Y. Kobara and M. Ueji: J. Weed Sci. Technol. 51, 69-81 (2006) (in Japanese).

4) T. Iwafune, K. Inao, T. Horio, N. Iwasaki, A. Yokoyama and T. Nagai: J. Pestic. Sci. 35, 114-123 (2010).

5) T. K. Phong, K. Yoshino, K. Hiramatsu, M. Harada and T. Inoue: Paddy Water Environ. 8, 361-369 (2010).

6) K. Inao and Y. Kitamura: Pestic. Sci. 55, 38-46 (1999).

7) K. Inao, Y. Ishii, Y. Kobara and Y. Kitamura: J. Pestic. Sci. 26, 229-235 (2001).

8) K. Inao, H. Mizutani, Y. Yogo and M. Ikeda: J. Pestic. Sci. 34, 273-282 (2009).

9) H. Watanabe and K. Takagi: Environ. Technol. 21, 1379-1391 (2000).

10) H. Watanabe and K. Takagi: Environ. Technol. 21, 1393-1404 (2000).

11) H. Watanabe, K. Takagi and S. H. Vu: Pest Manag. Sci. 62, 20-29 (2006).

12) K. Inao, Y. Ishii, Y. Kobara and Y. Kitamura: J. Pestic. Sci. 28, 24-32 (2003).

13) K. Inao, T. Hojyo, H. Annoh, S. Miyazaki, T. Saito and H.-D. Park: J. Pestic. Sci. 36, 413-427 (2011) (in Japanese).

14) N. Iwasaki, K. Inao, T. Iwafune, T. Horio and H. Obara: Limnology 13, 221-235 (2012).

15) http://www.env.go.jp/water/dojo/sui-kaitei.pdf (Accessed 1 Jul., 2015) (in Japanese).

16) M. Sudo, Y. Goto, T. Okajima, R. Horiuchi and H. Odani: J. Pestic. Sci. 37, 140-147 (2012).

17) The Japanese Society of Irrigation: Drainage and Rural Engineering (ed.): "Advanced Paddy Field Engineering," Shinzan-sha Sci. \& Tech., Tokyo, 1999.

18) http://www.maff.go.jp/j/council/seisaku/nousin/bukai/h24_4/pdf/ ref-data2-1.pdf/ (Accessed 1 Jul., 2015) (in Japanese).

19) http://www.env.go.jp/water/noyaku/seitaiken01/honbun.pdf (Accessed 1 Jul., 2015) (in Japanese).

20) J. L. Schnoor (ed.): "Environmental Modeling: Fate and Transport of Pollutants in Water, Air, and Soil," Wiley-Interscience, New York, pp. 470-473, 1996.

21) http://nlftp.mlit.go.jp/ksj/index.html (Accessed 1 Jul., 2015) (in Japanese).

22) http://agrimesh.dc.affrc.go.jp/soil_db (Accessed 1 Jul., 2015) (in Japanese).

23) http://www.acis.famic.go.jp/syouroku/bensulfuron-methyl/index. htm (Accessed 1 Jul., 2015) (in Japanese).

24) http://www.acis.famic.go.jp/syouroku/bromobutide/index.htm (Accessed 1 Jul., 2015) (in Japanese).

25) http://www.acis.famic.go.jp/syouroku/daimuron/index.htm (Accessed 1 Jul., 2015) (in Japanese).

26) http://www.e-stat.go.jp/SG1/estat/List.do?lid $=000001108528$ (Accessed 1 Jul., 2015) (in Japanese).

27) Japan Plant Protection Association (ed.): “Nouyaku-youran 2013," Japan Plant Protection Association, Tokyo (in Japanese).

28) http://www.e-stat.go.jp/SG1/estat/List.do?lid=000001106532 (Accessed 1 Jul., 2015) (in Japanese).

29) S. H. Vu, S. Ishihara and H. Watanabe: Pest Manag. Sci. 62, 11931206 (2006). 